\title{
Limitations to the dynamics of pharmaceutical care practice among community pharmacists in Enugu urban, southeast Nigeria
}

This article was published in the following Dove Press journal:

Integrated Pharmacy Research and Practice

5 June 2015

Number of times this article has been viewed

\author{
Brian O Ogbonna' \\ Charles C Ezenduka' \\ Jeffrey S Soni² \\ Azuka C Oparah² \\ 'Department of Clinical Pharmacy \\ and Pharmacy Management, Faculty \\ of Pharmaceutical Sciences, Nnamdi \\ Azikiwe University Awka, Awka, \\ Nigeria; ${ }^{2}$ Department of Clinical \\ Pharmacy and Pharmacy Practice, \\ Faculty of Pharmacy, University of \\ Benin, Benin City, Nigeria
}

Background: The introduction of pharmaceutical care in Nigeria has been faced with many challenges in addition to limited information regarding the practice.

Objective: This study aimed to determine the barriers encountered by community pharmacists in Nigeria in the provision of pharmaceutical care.

Methods: A cross-sectional descriptive survey was carried out in Enugu urban, southeast Nigeria. Data were collected using pretested and structured 5-point Likert scale questionnaires that were self-administered to the respondents. Data were analyzed using descriptive statistics.

Results: The 78 community pharmacists comprised 62 males and 16 females. Out of the 78 respondents, $69(88.5 \%)$ had the basic Bachelor of Pharmacy degree while three $(3.9 \%)$ had Fellowship, Master's, and Doctor of Pharmacy degrees respectively. The mean number of years of practice was $8.2( \pm 0.6)$. The key limitations to the implementation of pharmaceutical care were: pharmacists' attitude and lack of pharmaceutical care skills, as well as resource and system-related constraints. Others challenges were interprofessional and academic obstacles like lack of collaboration (66.6\%) and lack of role models (42.1\%). Most of the respondents (81\%) were strongly willing to adopt and implement pharmaceutical care, while $19.2 \%$ were not strongly willing to practice pharmaceutical care.

Conclusion: Despite limitations to practice, community pharmacists in the area are very inclined to implement pharmaceutical care in the private sector to improve patients' quality of life.

Keywords: patient medication care, practice, pharmacists, community pharmacy, Nigeria

\section{Introduction}

There has been an increasing need to improve community pharmacy operations to match the demands of the 21 st century. Many pharmacists have chosen to embrace the pharmaceutical care model in their practice sites in place of the usual traditional care to meet patients' health care system needs. There is also an increasing need to integrate pharmaceutical care activities into community practice. Therefore, colleges of pharmacy and community pharmacists need good collaboration to increase pharmaceutical care awareness to prepare pharmacists for today's practice. From the onset, the Accreditation Council for Pharmaceutical Education (ACPE) standards and guidelines emphasized the necessity for 4th year. Advanced Pharmacy Practice Experiences (APPEs), which focus on patient care and emphasized the pharmaceutical care model. Pharmaceutical care is the responsible provision of drug therapy for the purpose of achieving definite outcomes that improve a patient's quality of life. ${ }^{1,2}$ It is also defined as a patient-centered, outcome-oriented pharmacy practice that requires the pharmacist to work in collaboration with the patient and the patient's other health
Correspondence: Brian O Ogbonna Department of Clinical Pharmacy and Pharmacy Management, Faculty of Pharmaceutical Sciences, Nnamdi Azikiwe University Awka, PMB 5025 Awka, No I-I5 Enugu-Onitsha Express Way, Awka, Anambra State, Nigeria

Tel +234803779 4206

Email bo.ogbonna@unizik.edu.ng 
care providers to promote health, prevent disease, and assess, monitor, initiate, and modify medication use. It ensures that drug therapy regimens are safe and effective. ${ }^{3}$ Irrational use of medicines has resulted in many life-threatening conditions and avoidable deaths in our hospitals., ${ }^{4,5}$

Pharmacists have great opportunities to make significant contributions in public health. They are readily accessible and are often consulted for health problems, especially those related to prescription drugs. They make recommendations to their clients and encourage them to participate in screenings to encourage early detection and prevention of diseases. Hence, health promotion should be an important part of pharmacy training, since pharmacists are strategically positioned to positively impact the health of individuals in their communities. They participate not only in curative medicine but also in preventive medicine. ${ }^{6,7}$ Community pharmacies refer patients to hospitals based on their health needs. They carry out primary preventive public health activities geared toward correcting modifiable risk factors and disease prevention at the community level.

There is a growing trend toward optimizing the medication use process (ie, pharmaceutical care). However, community pharmacy practice in Nigeria is still not fully utilized and is in its nascent stage. Progress has been made in cognitive service remuneration and some score carding based upon improvements in economic, clinical, and humanistic patient outcomes. However, the customary success metrics for community pharmacies remain focused upon the processing of prescriptions, rather than the outcome associated with appropriate medication management by pharmacists. ${ }^{8-10}$ The Asheville Project (involving 12 pharmacies, 85 patients with diabetes) found that patients receiving pharmaceutical care interventions fared better than a comparison group. The Asheville Project started in March 1997. Services performed by community pharmacists include patient education and training, clinical assessment, monitoring, follow-up and referral. Participating patients had lower overall health costs, missed fewer days of work/school, and required less intensive health care interventions. Project ImPACT as it was popularly called, focused on community pharmacists' interventions (26 pharmacies) with patients suffering from dyslipidemias (397 patients). With this pre-post comparison group design, the rates of persistence, compliance, and attainment of clinical goals were demonstrated using pharmaceutical care. ${ }^{11-13}$

The pharmacist cooperates with the patient and other health care professionals but does not have sole responsibility for the medication use process. Pharmaceutical care is a professional practice that addresses a unique set of health care needs not currently addressed by other practitioners. A practice is the application of a specialized set of knowledge and skills to resolve specific patient needs in accordance with the standards accepted by both the profession and society. These standards require that the patient care process be completed in its entirety for each patient. Opposition by some medical doctors in government hospitals has been reported. ${ }^{14}$ However, patient-oriented pharmacy practice is gradually gaining grounds in Nigeria following the advent of pharmaceutical care through research, public awareness, and advocacy. This study was conducted because understanding the barriers is vital to generating information that will help improve pharmaceutical care practice and bridge the gap created by the limitations in Nigeria. The objective of this study was to determine the barriers encountered by community pharmacists in the provision of pharmaceutical care in Nigeria.

\section{Materials and methods Study site and setting}

Enugu is over a century old, and was the capital of the old southeastern region of Nigeria, but is presently the capital of Enugu State. The state has a population of more than $3,257,298$ people, with over $40 \%$ of this population residing in Enugu. The population is still growing due to urbanization and the presence of basic amenities like good roads, pipe-borne water, electricity, affordable housing, hospitals, schools, and others. It is also centrally located with Anambra state on the west, Ebonyi state to the east, Benue and Kogi states to the north, and Abia and Imo states located to the south. This helps in providing easy accessibility and allows the influx of people from the other geopolitical zones. The population is predominantly made up of Ibos mixed with other tribes. The two main languages are Igbo, which is the native language, and English, the official language.

\section{Description of pharmacists at the study site}

The operations and activities of pharmacists here are regulated by the Pharmacists Council of Nigeria (PCN). The pharmacists are a source of health information to the public and they carry out free consultations in their premises. They also carry out a number of health promotion services that include health education, and health screening for hypertension, diabetes, and malaria. Some pharmacists carry out intervention studies and educate clients on weight management, smoking cessation, withdrawal from substance abuse, good nutrition, and chronic disease management in collaboration with other members of the health care team, especially the 
physicians, etc. However, they are very limited in number compared to the ever-teaming population. There are approximately 16,000 pharmacists to care for over 170 million people in Nigeria giving rise to a pharmacist:human ratio of $1: 10,625 .{ }^{15}$ This population comprises those who have left the country in search of greener pasture abroad.

\section{Study design}

The study was a cross-sectional, descriptive survey conducted using a structured questionnaire on a 5-point Likert scale. The study population comprised registered community pharmacists practicing within Enugu metropolis who were selected based on selected criteria.

\section{Inclusion criteria}

- community pharmacists residing and practicing within Enugu metropolis;

- community pharmacists registered with the PCN;

- those who have practiced for at least more than 1 year in community pharmacy;

- those who gave their informed consent to participate in the study.

\section{Exclusion criteria}

- community pharmacists who did not give their informed consent to participate in the study;

- those who are not duly registered with PCN;

- those who have not practiced for up to 1 year;

- community pharmacists practicing outside Enugu metropolis.

\section{Data collection}

Primary data collection was carried out through self-administered structured questionnaires that tend to measure the intensity of the feeling of the respondents with respect to the information being sought. Questionnaires were administered to the respondents and collected back on agreed dates. Names were omitted from the questionnaires to prevent any form of identification or bias.

\section{Questionnaire development}

The questionnaire was broadly divided into two parts: the classification section to capture demographic data and the second part with questions relating to the subject matter under study. The number of questions was minimized, and questions were made short and clear to avoid ambiguity. Leading questions relating to the subject matter were avoided in order not to influence the thought of the respondents while covering the subject area. Open-ended and leading questions were used for flexibility and to allow the respondents to state their position for greater validity of the instrument. Questions asked in the questionnaire were complete sentences. During the pilot study, every question was filled with an interview to know if the response to any questionnaire item actually represents the views on the subject of discuss. The test-retest technique was further used to establish the reliability of the questionnaire. The questionnaire was constructed in English and organized into five domains with a total of 21 items. It was self-administered.

\section{Administration of questionnaire and data collection}

A total of 113 pharmacists were eligible for the study and out of these, 105 gave their informed consent. A pilot study was conducted with 15 respondents who did not participate in the main study. All the remaining 90 respondents took part in the main study; 84 were returned while six out of the returned questionnaires were not properly filled, resulting in 78 returned questionnaires available for study. The questionnaire was first field-tested (pilot study) by administering them to 15 community pharmacists practicing within the metropolis for construct and content validation. The questionnaires were self-administered. Respondents were revisited on agreed dates to collect them back.

\section{Sampling methods}

All the 90 registered community pharmacists who gave their informed consent participated in the study. This was to increase reliability, considering the limited population of community pharmacists in the area.

\section{Data analysis}

Raw data collected were entered into Microsoft Excel, double checked for accuracy, and analyzed using descriptive statistics and Microsoft Excel.

\section{Ethical consideration}

Ethical approval was obtained from the research and ethics committees of the Nnamdi Azikiwe University Teaching Hospital (NAUTH), Nnewi, Anambra State, Nigeria, and the Enugu State University Teaching Hospital (ESUTH), Enugu, Enugu State, Nigeria, respectively, as part of a larger study on the impact of pharmaceutical care interventions on Type 2 diabetes management in Nigeria. Informed consent was also obtained from all the community pharmacists who participated in the study. 


\section{Results}

Out of the 90 questionnaires distributed, 84 were filled and collected back, resulting in a response rate of $93 \%$. Six out of the 84 returned questionnaires that were not properly filled were discarded and a total of 78 questionnaires were used for the study as shown in Figure 1. Table 1 lists the background qualifications of respondents. The standard mean of the frequency distribution for the number of years of community practice was $8.2 \pm 0.6$ while the questionnaire return rate was $99 \%$.

\section{Discussion}

The respondents are predominantly young pharmacists with the first degree in pharmacy who have practiced for less than 10 years. However, just a little of this population have practiced for more than 10 years and 20 years, respectively. The limitations to pharmaceutical care among respondents include: poor pharmacists' attitude toward pharmaceutical care practice, resource-related constraints, system-related constraints, interprofessional obstacles, and academic obstacles as tabulated in Table 2 . The study is similar to several studies conducted on the limitations to pharmacists practice by Rovers et al. ${ }^{16}$ It supports the results obtained from the United States and Europe where time and money were reported as key limitations by Miller and Ortmeier and Van Mill et al. ${ }^{17,18}$ This could also be associated with very few role models in this practice area in Nigeria presently.
However, the lack of pharmaceutical care skills could be associated with the misconception that having the knowledge of pharmaceutical care is synonymous with the skills but knowledge could be acquired at a point while skills take longer time to attain. Professional development and academic qualification could be a factor that should not be overlooked in Nigeria. The place of skills and manpower development should be given strong considerations as a driving force for positive change, especially in any developing economy. Resource-related constraints, namely, space, finance, and qualified personnel contribute to the limitations coupled with system-related barriers, namely, lack of reimbursement, patients' demand, and acceptance by physicians. This is similar to results obtained by Awad et al ${ }^{19}$ and May, ${ }^{20}$ which reported resource- and system-related constraints as key limitations. Farris and Schopflocher suggested the non availability of trained supportive staff for minor dispensing work as another limitation that affects the successful implementation of pharmaceutical care. ${ }^{21}$

Further work could focus on the rate and levels of human resources development for the implementation of pharmaceutical care and determination of the levels of its adoption. Pharmacists' attitudes, lack of necessary skills, and resourcerelated constraints were also identified as limitations to the implementation of the practice in the area under study. The study shows that pharmaceutical care skills, like clinical problem solving, therapeutics, and communication and

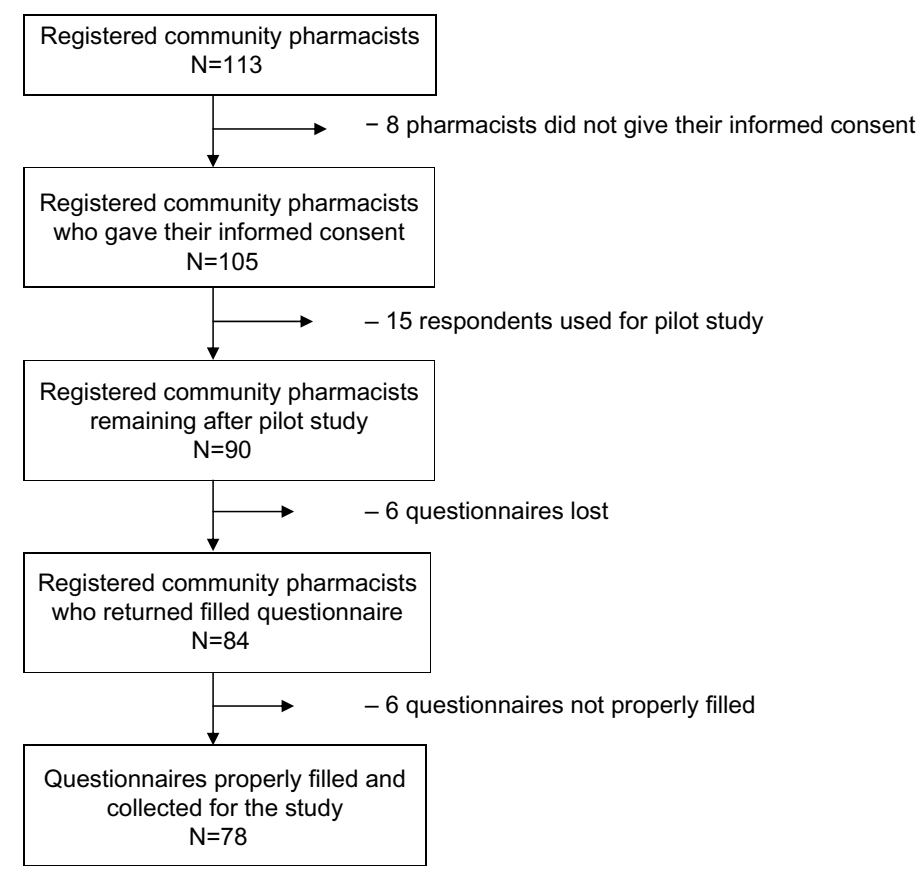

Figure I Schematic representation depicting how participants were recruited. 
Table I Demographic characteristics of participants

\begin{tabular}{ll}
\hline Characteristics & $\mathbf{n}(\%)$ \\
\hline Qualification & \\
BPharm (Bachelor of Pharmacy) & $69(88.5)$ \\
Pharm D (Doctor of Pharmacy) & $3(3.9)$ \\
MPharm (Master of Pharmacy) & $3(3.9)$ \\
FPCPharm (Fellowship) & $3(3.9)$ \\
Total & $78(100)$ \\
Years of practice & \\
I-I0 & $60(77.0)$ \\
II-20 & $15(19.0)$ \\
$21-30$ & $3(4.0)$ \\
$3 I-40$ & 0 \\
Total & $78(100.0)$ \\
\hline
\end{tabular}

documentation skills are still lacking among pharmacists. This is understandable as the introduction of pharmaceutical care into the undergraduate curricula started less than a decade ago. The younger generations of pharmacists are more familiar with the practice than those who graduated more than 10 years ago. This underscores the need for training and retraining through continuing education and exchange programs as obtainable in developed countries. ${ }^{22}$

All domains of resource-related constraints, namely, time, finance, space, personnel, and management showed negative responses, an indication of limitations to the pharmaceutical care practice. Lack of space in community pharmacies limit confidentiality, which is very vital in consultations, while shortage of skilled and trained personnel increase work load and reduces patients' counseling and consultation time. Acceptance of community pharmacists' activities by physicians borders on the level of awareness and understanding between the parties. However, most physicians feel that their professional duties are being threatened, while others embrace it as a complimentary role that borders on team work toward improving patients' treatment outcomes. These limitations are consistent with observations by Rovers et al. ${ }^{16}$

Table 2 Limitations encountered by respondents and their willingness to adopt the practice

\begin{tabular}{|c|c|c|c|c|c|c|}
\hline $\begin{array}{l}\text { Responses obtained from } \\
\text { questionnaire covered } \\
\text { these items below }\end{array}$ & $\begin{array}{l}\text { Strongly } \\
\text { agree, N (\%) }\end{array}$ & $\begin{array}{l}\text { Tend to } \\
\text { agree, } \mathbf{N}(\%)\end{array}$ & $\begin{array}{l}\text { Neither agree nor } \\
\text { disagree, } \mathbf{N}(\%)\end{array}$ & $\begin{array}{l}\text { Tend to } \\
\text { disagree, } \mathbf{N}(\%)\end{array}$ & $\begin{array}{l}\text { Strongly } \\
\text { disagree, N (\%) }\end{array}$ & $\mathbf{N}$ \\
\hline \multicolumn{7}{|l|}{ Pharmacist attitude } \\
\hline Lack of comprehension & $21(29.2)$ & $24(33.2)$ & $3(4.2)$ & $3(4.2)$ & $21(29.2)$ & 72 \\
\hline Misconception & $21(30.4)$ & $15(21.7)$ & $9(13.1)$ & $6(8.7)$ & $18(26.1)$ & 69 \\
\hline Fear of change & $15(23.8)$ & $33(52.4)$ & 0 & $9(14.3)$ & $6(9.5)$ & 63 \\
\hline Lack of motivation & $24(33.4)$ & $12(18.2)$ & $6(9.1)$ & $9(13.6)$ & $15(22.7)$ & 66 \\
\hline Inertia & $18(25.0)$ & $12(16.7)$ & $15(20.8)$ & $18(25.0)$ & $9(12.5)$ & 72 \\
\hline Personal energy & $6(I I . I)$ & $9(16.7)$ & $9(16.7)$ & $12(22.2)$ & $18(33.3)$ & 54 \\
\hline \multicolumn{7}{|c|}{ Lack of pharmaceutical care skills } \\
\hline Therapeutics & $3(4.6)$ & $12(18.2)$ & $3(4.6)$ & $18(27.2)$ & $30(35.4)$ & 66 \\
\hline Clinical problem solving & $12(19.1)$ & $3(4.8)$ & $9(14.2)$ & $12(19.1)$ & $27(42.9)$ & 63 \\
\hline Communication skills & $9(13.7)$ & $3(4.5)$ & $3(4.5)$ & $21(31.8)$ & $30(45.5)$ & 66 \\
\hline Documentation & I5 (2।.7) & $12(17.4)$ & $12(17.4)$ & $12(17.4)$ & $18(26.1)$ & 69 \\
\hline Drug information & $15(25.0)$ & $3(5.0)$ & $12(20.0)$ & $9(15.0)$ & $21(35.0)$ & 60 \\
\hline \multicolumn{7}{|l|}{ Resources related constraints } \\
\hline Time & $9(13.6)$ & $30(45.5)$ & $6(9.1)$ & $9(13.6)$ & $12(18.2)$ & 66 \\
\hline Finance & $24(36.4)$ & $15(22.7)$ & $15(22.7)$ & $9(13.6)$ & $3(4.6)$ & 66 \\
\hline Space & $27(40.9)$ & 0 & $21(31.8)$ & $12(18.2)$ & $6(9.1)$ & 66 \\
\hline Personnel & $24(38.1)$ & I8 (28.6) & $9(14.3)$ & $12(19.0)$ & 0 & 63 \\
\hline Management & I8 (27.3) & I8 (27.3) & $15(27.7)$ & $6(9.1)$ & $9(13.6)$ & 66 \\
\hline \multicolumn{7}{|l|}{ System related constraints } \\
\hline Reimbursement & $36(57.0)$ & $3(4.8)$ & I8 (28.6) & $3(4.8)$ & $3(4.8)$ & 63 \\
\hline Patient demand & $15(25.0)$ & $15(25.0)$ & $18(30.0)$ & $6(10.0)$ & $6(10.0)$ & 60 \\
\hline Acceptance by physicians & $26(55.3)$ & $3(6.4)$ & $12(25.5)$ & $3(6.4)$ & $3(6.4)$ & 47 \\
\hline \multicolumn{7}{|l|}{ Interprofessional obstacles } \\
\hline Lack of collaboration & $36(66.6)$ & $3(5.6)$ & $6(11.1)$ & $3(5.6)$ & $6(11.1)$ & 54 \\
\hline Board of pharmacy & $30(47.6)$ & $6(9.5)$ & $6(9.5)$ & $6(9.5)$ & $15(23.9)$ & 63 \\
\hline Faculties of pharmacy & $21(38.9)$ & $12(22.2)$ & $9(16.7)$ & $3(5.5)$ & $9(16.7)$ & 54 \\
\hline \multicolumn{7}{|l|}{ Academic obstacles } \\
\hline Lack of role models & $24(42.1)$ & $6(10.5)$ & $9(15.8)$ & $3(5.3)$ & $15(26.3)$ & 57 \\
\hline $\begin{array}{l}\text { Willingness to carryout } \\
\text { pharmaceutical care }\end{array}$ & $63(80.8)$ & $15(19.2)$ & 0 & 0 & 0 & 78 \\
\hline
\end{tabular}


Outstanding interprofessional obstacles of interest in this study include lack of collaboration, limitations from Board of Pharmacy due to poor implementation, and enforcement of relevant issues bordering on the progress of the profession. This takes its negative toll on the faculties of pharmacy and development of pharmacy education. A good example is the delay in the enforcement of the Doctor of Pharmacy (Pharm D) program (a clinically oriented pharmacy degree) in all the pharmacy schools in Nigeria. Out of over 12 tertiary schools training pharmacists within the country, only one of them offers the Pharm D program presently. Pharmaceutical care is still at the foundation stage in Nigeria and lacks the requisite number of role models and practitioners needed to match the demand and serve as a driving force to facilitate the training and retraining process required to meet the manpower need of the teaming population. Studies suggest that lack of role models coupled with very limited clinical exposure to clinical practice due to lack of skilled clinical pharmacists, policy framework, and poor pharmacy practice settings, are among the leading limitations to the implementation of pharmaceutical care. A study conducted by Tayo $^{23}$ revealed the huge gap in skilled human resources need for the pharmaceutical sector in the West African subregion. ${ }^{24}$

Since most of the community pharmacies are owned by private practitioners, system-related constraints like lack of reimbursement are greatly overlooked due to the competitive business climate in order to break even. This suggests why most of the community pharmacists do not spend much time in rendering some services that could be helpful to their clients. ${ }^{25,26}$

All the community pharmacists are strongly willing to adopt and practice pharmaceutical care. This finding is consistent with a similar study in Kuwait that reported total willingness. ${ }^{27}$ The implication is that the government could take advantage of the willingness of these practitioners by enforcing targeted educational interventions and incorporation of remunerations for services rendered as obtainable in some of the civilized nations. ${ }^{21,22,28}$ Such an action requires technical support from the academia. ${ }^{29}$ Berger and Grimley examined pharmacists' readiness to render pharmaceutical care using the trans-theoretical model, which suggests that five stages of voluntary behavior change exist: precontemplation, contemplation, preparation, action, and maintenance..$^{30}$ Okonta et al in southeastern Nigeria suggested that technical collaboration of health professionals and health facility management with pharmacists' regulatory authorities will promote pharmaceutical care practice and bridge most of the gaps. ${ }^{31}$

\section{Limitations of the study}

A few limitations exist in this study. The questionnaire does not allow the investigator to determine the respondents' sincerity, apparent reluctance, or even their evasiveness as obtainable through interview. Open-ended questions allow for better expression of respondents' view. However, it could increase the risk of misinterpretation. Closed or leading questions, on the other hand, minimize the risk of misinterpretation by the investigator but the categories will need to be exhaustive and mutually exclusive. A combination of the two has been used to minimize the limitations associated with the validity, reliability, and usability of the questionnaire. All these domains may not have been completely captured.

\section{Conclusion}

This study determines the barriers to pharmaceutical care practice encountered by community pharmacists in Nigeria. The findings reflect respondents' opinion as identified after the survey. Study result shows that pharmacists' attitude, system-related constraints, and interprofessional obstacles are the barriers to the implementation of pharmaceutical care identified by the pharmacists. These barriers further limit patients' access to pharmaceutical care services in the region. However, respondents demonstrated great willingness to adopt the practice. There is a huge gap between improvement and development of pharmaceutical care practice in Nigeria and global best practices. Continuous educational interventions and experiential training to enhance exposure to clinical practice for encouraging the output of skilled community pharmacists very skillful in patient care could be a veritable way of bridging the gap. This will further encourage the availability of pharmaceutical care practitioners with enough exposure in clinical practice. The government can contribute positively by creating practice-friendly, enabling environment and good pharmacy practice settings at all levels of health care. Training more practitioners through sponsorship and scholarships will be of immense benefit. This will help in sustaining manpower development, ensuring the presence of role models, and training the trainers to anchor institutional training at both undergraduate and postgraduate levels. This is critical to the success and development of pharmaceutical care practice at all spheres of pharmacy practice in Nigeria.

\section{Acknowledgments}

The authors thank the Research and Ethics Committee of Nnamdi Azikiwe University Teaching Hospital and Enugu State University Teaching Hospital for granting all the necessary approval to carry out this work. 


\section{Disclosure}

The authors report no conflicts of interest in this work.

\section{References}

1. Hepler CD, Strand LM. Opportunities and responsibilities in pharmaceutical care. Am J Pharm. 19910;47:533-543.

2. Bruce LL. Introduction to Public Health Pharmacy. Vol 1. Sudbury, MA: Jones and Bartlett; 2006:131-135.

3. Accreditation Council for Pharmacy Education (ACPE) [homepage on the Internet]. Available from: https://www.acpe-accredit.org/. Accessed January 23, 2006.

4. Manasse HR Jr. Medication use in an imperfect world: drug misadventuring as an issue of public policy, part 1. Am J Hops Pharm. 1989;46: 929-944.

5. Ernst FR, Grizzle AJ. Drug-related morbidity and mortality: updating the cost of illness model. J Am Pharm Assoc. 2001;41(2):192-199.

6. Moody MW. Health promotion and health education. In: Wind Field AJ, Richards RM, editors. Professional Practice 2nd Education. London: Churchill Livingstone; 1998:1-40.

7. Walker R. Pharmaceutical public health: the end of the pharmaceutical care. Pharm J. 2000;264(2035):340-341.

8. Cranor CW, Christensen DB. The Asheville Project: Short-Term Outcomes of a Community Pharmacy Diabetes Care Program. $J$ Am Pharm Assoc. 2003;43:149.

9. Cranor CW, Bunting BA, Christensen DB. The Ashville Project: long-term clinical and economic outcomes of a community pharmacy diabetes care program. J Am Pharm Assoc. 2003;43:160.

10. Cranor CW, Christensen DB. The Ashville Project: factors associated with outcomes of a community pharmacy diabetes program. J Am Pharm Assoc. 2003;43:149.

11. Hepler CD, Strand LM. Opportunities and responsibilities in pharmaceutical care. Am J Hosp Pharm. 1990;47:533-542.

12. Hepler CD. Pharmaceutical care. Pharm World Sci. 1996;18(6): 233-235.

13. Hepler CD. The clinical movement. Am J Pharm Educ. 1987;51: 369-385.

14. Erah PO, Nwazuoke JC. Identification of standards for pharmaceutical care in Benin City. Trop J Pharm Res. 2002;1(2):55-56.

15. Tayo F. Human resources needs for the provision of pharmaceutical services in the West African sub-region. West Afr J Pharm. 2007;20(1): 4-7.
16. Rovers JP, Currie JD, Hagel HP, McDonough RP, Sobotka JL. A Practical Guide to Pharmaceutical Care. 2nd ed. Washington DC: American Pharmaceutical Association; 2003.

17. Miller MJ, Ortmeier BG. Factors influencing the delivery of pharmaceutical services. Am Pharm. 1995;NS35(1):39-45.

18. Van Mill JWF, DeBoer WO, Tromp FJ. European barriers to the implementation of pharmaceutical care in community pharmacies: practice and research around the world. Ann Pharmacother. 2005;39: 1539-1541.

19. Awad A, Al-Ebrahim S, Abahussain E. Pharmaceutical care services in hospitals Kuwait. J Pharm Sci. 2006;9(2):10-18.

20. May RM. Barriers to pharmaceutical care in acute care setting. Am $J$ Hosp Pharm. 1993;50:1608-1611.

21. Farris KB, Schopflocher DP. Between intention and behavior: an application of community pharmacists' assessment of pharmaceutical care. Soc Sci Med. 1999;49:55-56.

22. Professional Practice Standards; Version 3; 2006:113-119. Pharmaceutical Society of Australia. Available from: https://www.psa.org.au/ download/codes/prof-practice-standards-v3.pdf. Accessed May 26, 2015.

23. Tayo F. Human resources needs for the provision of pharmaceutical services in the West African sub-region. West Afr J Pharm. 2007;20(1): 4-7.

24. Al-shagha WN, Zaira M. Pharmaceutical care management: a modern approach to providing seamless and integrated health care. Int $J$ Health Care Qual Assess.

25. The Royal Pharmaceutical Society. Guidance for development of health promotion by community pharmacists. Pharm J. 1998;261:771-774.

26. Bisselp JJ. Public health and pharmacy: a critical review. Crit Public Health. 2006;11:159-160.

27. Abdelmoneim A, Shareefa A, Eman A. Pharmaceutical care services in hospitals of Kuwait. J Pharm Sci. 2006;9(2):149-157.

28. Knapp KK, Paarola FG, Maine LL, Sorefman EE, Politer RM. Availability of primary care provider and pharmacists in US. $J$ Am Pharm Assoc (Wash). 1999;39(2):127-135.

29. McDonough RP. Interventions to improve patient pharmaceutical care outcomes. J Am Pharm Assoc. 1996;536:453-466.

30. Berger BH, Grimley D. Pharmacist readiness for rendering pharmaceutical care. A paper presented at: Annual Meeting of the American Pharmaceutical Association. Los Angeles, CA; 1997.

31. Okonta JE, Okonta EO, Ofoegbu TC. Barriers to Implementation of pharmaceutical care by pharmacists in Nsukka and Enugu metropolis of Enugu state. J Basic Clin Pharm. 2012;1:2-4.
Integrated Pharmacy Research and Practice

\section{Publish your work in this journal}

Integrated Pharmacy Research and Practice is an international, peer-reviewed, open access, online journal, publishing original research, reports, reviews and commentaries on all areas of academic and professional pharmacy practice. This journal aims to represent the academic output of pharmacists and pharmacy practice with particular focus on integrated care. All papers are carefully peer reviewed

\section{Dovepress}

to ensure the highest standards as well as ensuring that we are informing and stimulating pharmaceutical professionals. The manuscript management system is completely online and includes a very quick and fair peer-review system, which is all easy to use. Visit http://www.dovepress.com/testimonials.php to read real quotes from published authors. 